\title{
Lung function and the response to exercise in systemic sclerosis
}

\author{
SIMON GODFREY ${ }^{1}$, RODNEY BLUESTONE, AND \\ B RENDA E. HIGGS \\ From the Department of Medicine, Royal Postgraduate Medical School, London, W.12
}

\begin{abstract}
Cardiopulmonary function has been studied at rest and during graded exercise in 11 patients with systemic sclerosis. All patients had multi-system disease, five complained of breathlessness, and four had radiographic evidence of pulmonary fibrosis. All patients had gross effort intolerance. Lung volumes were reduced in half the patients, as was the transfer factor for $\mathrm{CO}$ when corrected for lung volume. Airway resistance was normal. Four patients hyperventilated on exercise, but the tidal volume was normal; three developed arterial desaturation during exercise. Six patients had an excessive elevation of blood lactate on exercise and three of these had evidence of muscle disease. Analysis of the exercise data suggested that in seven patients cardiac output and dead space were normal. In four patients there was a pattern of normal cardiac output, increased dead space, and increased venous admixture, suggesting ventilation/perfusion imbalance. There was no correlation between the results of the physiological tests and the extent of clinical involvement with the disease. The possible reasons for this and for the effort intolerance are reviewed.
\end{abstract}

It is known that the lungs are often affected in connective tissue diseases, including systemic sclerosis. In this condition the lung involvement is usually a progressive type of pulmonary fibrosis, the features of which have recently been reviewed by Weaver, Divertie, and Titus (1967). The commonest symptom of pulmonary disorder is breathlessness on exertion. Various explanations have been offered to account for this in terms of disordered physiology, but such observations as timed spirometry, lung volumes, and transfer of carbon monoxide, performed at rest, cannot provide the full picture. There are relatively few studies on the response to exercise of patients with systemic sclerosis, and these have been concerned only with total ventilation and arterial oxygen saturation (Ritchie, 1964).

We have studied a group of patients attending a routine rheumatology department, both clinically and by means of pulmonary function tests. These included both conventional studies at rest and the response to graded exercise on a cycle ergometer. We have explained the use of a 'bloodless' exercise test at some length because it is a relatively new concept, and we have stressed the reassuring information it can give when normal.

${ }^{1}$ Address for correspondence: Institute of Diseases of the Chest, Brompton, London, S.W.3

\section{METHODS}

All patients had systemic sclerosis diagnosed clinically with the characteristic skin changes and the other features described below. There were 11 patients, all but one of whom were women. The response to exercise was studied in all patients, timed spirometry was measured in 10 , lung volumes in 9 , and the transfer factor for carbon monoxide in 10.

The forced expiratory volume in the first second (F.E.V.1) and the relaxed vital capacity (V.C.) were measured with a bellows spirometer (Collins, McDermott, and McDermott, 1964) by the method of Freedman and Prowse (1966). A whole body plethysmograph was used to measure the total lung capacity (T.L.C.) and specific airways conductance (SGaw), the reciprocal of airway resistance divided by the lung volume at which it was measured (Guyatt, Alpers, Hill, and Bramley, 1967). The transfer of carbon monoxide was measured by the single-breath method and the results were expressed in terms of Krogh's time constant $\left(\mathrm{k}_{\mathrm{CO}}\right)$ and the transfer factor (TLco) in the way described by McGrath and Thomson (1959).

Each patient was studied during progressive exercise on a cycle ergometer (Elema-Schönander) by the method described by Jones, Campbell, McHardy, Higgs, and Clode (1967). The patient cycled at the selected work load while mixed expired gases were monitored for $\mathrm{O}_{2}$ (Servomex DCL) and $\mathrm{CO}_{2}$ (URAS, CPI). When these gases reached steady levels, expired 
gas was collected in a large Tissot spirometer over at least one minute. During the collection, end-tidal $\mathrm{CO}_{2}$ was sampled at the mouth, and immediately after the collection the mixed venous $\mathrm{PCO}_{2}\left(\mathrm{P}_{\overline{\mathrm{v}}} \mathrm{CO}_{2}\right)$ was measured by the rebreathing method (Jones et al., 1967). The electrocardiogram was recorded throughout. In six of the studies, arterial $\mathrm{O}_{2}$ saturation was determined throughout by means of an ear oximeter (Atlas E.M. 54) using the technique of Lal, Gebbie, and Campbell (1966). The work load was then increased and the procedure was repeated until the patient was unable to continue.

If analysis of the exercise test suggested an abnormal response, the study was repeated on another occasion and arterial blood was sampled through an indwelling polyethylene cannula during the gas collection period. The samples were analysed for $\mathrm{PCO}_{2}$ with a Severinghaus type of electrode and with a Beckman Macro-electrode (modified Clark) for Po2. All analytical apparatus was frequently calibrated with gases whose composition was measured with a Lloyd-Haldane apparatus.

Arterial blood lactate was measured in three subjects by the enzymatic method (Hohorst, 1957).

CALCULATIONS In order to simplify the analysis of the results, all values of F.E.V.1, V.C., T.L.C., and Thco have been expressed in absolute terms and as percentages of the normal values, predicted from the patient's physical characteristics by means of standard nomograms (Needham, Rogan, and McDonald, 1954 ; Cotes, 1965) suitably adjusted to B.T.P.S. Minute ventilation $\left(V_{E}\right)$, tidal volume $(V t)$, oxygen consumption $\left(\dot{\mathrm{V}} \mathrm{O}_{2}\right)$, and carbon dioxide production $\left(\dot{\mathrm{V}} \mathrm{CO}_{2}\right)$ were calculated by standard physiological methods.

The analysis of the bloodless exercise test has been fully described by McHardy, Jones, and Campbell (1967) and by Jones (1967). The basis of this approach is that the difference between $\mathrm{P} \mathrm{CO}_{2}$ and mixed expired $\mathrm{PCO}_{2}\left(\mathrm{PeCO}_{2}\right)$ consists of a portion governed by cardiac output (Q), i.e., $\mathbf{P} \overline{\mathbf{v}} \mathrm{CO}_{2}-$ arterial $\mathrm{PCO}_{2}$ ( $\left.\mathrm{PaCO}_{2}\right)$, and a portion governed by the dead space/ tidal volume ratio $(\mathrm{Vd} / \mathrm{Vt})$, i.e., $\mathrm{PaCO}_{2}-\mathrm{PeCO}_{2}$. These relationships are given by the following versions of the Fick and Bohr equations:

$$
\begin{aligned}
& \text { Fick } \quad Q=\frac{\dot{\mathrm{VCO}}}{\mathrm{f}\left(\mathrm{P} \overline{\mathrm{V}} \mathrm{CO}_{2}-\mathrm{PaCO}_{2}\right)} \\
& \text { Bohr } \quad \mathrm{Vd} / \mathrm{Vt}=\frac{\mathrm{PaCO}_{2}-\mathrm{PeCO}_{2}}{\mathrm{PaCO}_{2}}
\end{aligned}
$$

(where $f$ is a function relating difference of content of $\mathrm{CO}_{2}$ in blood to differences in partial pressure).

We measure V́CO2, $\mathrm{P}_{\overline{\mathrm{V}} \mathrm{CO}_{2}}, \mathrm{PeCO}_{2}$, and $\mathrm{Vt}$ and we know $\mathrm{f}$; if we therefore assume any given value for $Q$ we can calculate $\mathrm{PaCO}_{2}$ and $\mathrm{Vd}$, and, similarly, if we assume any value for $\mathrm{Vd}$ we can calculate $\mathrm{PaCO}_{2}$ and $Q$. In these experiments we have calculated the value of $V d$ for the highest likely value of $Q$, which thus provides the highest value for $\mathrm{Vd}$, and we have calculated the value for $\mathbf{Q}$ corresponding to the lowest likely Vd which provides the lowest value for $Q$. The likely values for $Q$ and Vd were base on the normal range of values found in this labora tory (Higgs, Clode, McHardy, Jones, and Campbelī్ 1967 ; and unpublished data). The highest likely value for $Q$ has been taken as the mean $+20 \%$ (i.e $\vec{\phi}$ +1 S.D.) and the lowest likely value for $\mathrm{Vd}$ hasీ been taken as the mean-31\% (i.e., a value below which only $2-3 \%$ of normal subjects are found; this cannot be expressed in terms of standard deviation: because the Vd is not related normally to the $V t)$ Besides the extreme range of values for each subject predicted from the data in this way, it is also possible to predict a likely solution from the end-tidal Pcoî In subjects where airways obstruction is not a majof problem, the arterial $\mathrm{PCO}_{2}$ can be related to the end tidal $\mathrm{PCO}_{2}$ and we have used a corrected value (Jones, McHardy, Naimark, and Campbell, 1966 to calculate the likely $Q$ and Vd by means of the equations above. In studies when blood was taken, the actual values of $\mathbf{Q}$ and Vd were calculated.

Arterial oxygen saturation ( $\left.\mathrm{SaO}_{2}\right)$, whether deter mined directly or from ear oximetry, was compare with the expected value calculated from alveolar Pọp by the method of Lal et al. (1966). This information was also used to calculate the venous admixture ratiQ (Qva/Qt), i.e., the proportion of arterial blood effeco tively shunted past gas exchanging lung. The patien were also given $100 \% \mathrm{O}_{2}$ to breathe for long enoug to wash out the $\mathrm{N}_{2}$ from their lungs and the $\mathrm{PaO}$ at this time was used to calculate the "anatomicaf shunt, i.e., the portion of Qva/Qt not due to ventilas tion-perfusion imbalance.

When it was not measured directly, the rise if blood lactate was calculated by means of the balance equation for $\mathrm{CO}_{2}$ described by Clode (1966).

Because the results of exercise studies are more reliable at higher work levels, only the data obtained at the highest level for each patient will be presentect

\section{RESULTS}

The relevant physical charaoteristics of the patients are given in Table I. All the patients had skin manifestations of systemic sclerosis and all. had secondary Raynaud's phenomena; three had calcinosis and six had telangectasia. The duration

T A B L E I

\begin{tabular}{|c|c|c|c|c|c|}
\hline Patient & Sex & $\begin{array}{l}\text { Age } \\
(\mathbf{y r})\end{array}$ & $\begin{array}{l}\text { Height } \\
\text { (cm.) }\end{array}$ & $\begin{array}{c}\text { Weight } \\
\text { (kg.) }\end{array}$ & $\begin{array}{l}\text { Haemoglobin } \\
\text { (g. } / 100 \mathrm{ml} .)\end{array}$ \\
\hline $\begin{array}{l}\text { F.I. } \\
\text { M.H. } \\
\text { R.W. } \\
\text { K.B. } \\
\text { H.T. } \\
\text { S.P. } \\
\text { D.L. } \\
\text { E.P. } \\
\text { D.H. } \\
\text { B.Mc. } \\
\text { E.C. }\end{array}$ & $\begin{array}{l}\mathbf{F} \\
\mathbf{F} \\
\mathbf{F} \\
\mathbf{F} \\
\mathbf{F} \\
\mathbf{F} \\
\mathbf{F} \\
\mathbf{F} \\
\mathbf{F} \\
\mathbf{F} \\
\mathbf{M}\end{array}$ & $\begin{array}{l}65 \\
28 \\
39 \\
72 \\
33 \\
33 \\
42 \\
66 \\
65 \\
48 \\
59\end{array}$ & $\begin{array}{l}150 \\
169 \\
161 \\
161 \\
164 \\
162 \\
157 \\
164 \\
162 \\
162 \\
173\end{array}$ & $\begin{array}{l}65 \\
68 \\
60 \\
56 \\
65 \\
65 \\
58 \\
65 \\
65 \\
52 \\
78\end{array}$ & $\begin{array}{l}13.0 \\
13.0 \\
13.6 \\
14.6 \\
13.9 \\
13.5 \\
12.8 \\
13.5 \\
13.0 \\
13.8 \\
10.6\end{array}$ \\
\hline
\end{tabular}

PHYSICAL CHARACTERISTICS OF PATIENTS 
of systemic sclerosis prior to the present study varied from six months to 20 years (mean 7.8 years). Only five patients complained of shortness of breath and in two of these cases it was minimal. In the other three patients the breathlessness was moderate, but in no case was dyspnoea a presenting symptom. No patient complained of cough, sputum production, or haemoptysis. The chest radiograph was entirely normal in seven patients and showed moderate pulmonary fibrosis at the bases in three cases. In one patient (K. B.) the fibrosis was generalized. The male patient gave a history of angina of effort and he had ischaemic changes on his electrocardiogram (E.C.G.). One other patient had cardiomegaly on her chest radiographs and two patients had right bundle-branch block and T-wave inversion on the E.C.G. There was radiological evidence of oesophageal involvement in three. Three patients (K. B., D. L., and R.W.) had minor abnormalities of the skeletal muscle shown by electromyography and muscle biopsy. One patient had mild renal impairment.

ROUTINE LUNG FUNCTION TESTS The individual results of the measurements of lung volume, timed spirometry, and transfer of $\mathrm{CO}$ are given in Table

T A B L E II

\begin{tabular}{|c|c|c|c|c|c|c|c|}
\hline Patient & $\underset{\text { (1.) }}{\text { F.E.V.1 }}$ & $\begin{array}{l}\text { V.C. } \\
\text { (i.) }\end{array}$ & $\begin{array}{l}\text { T.L.C. } \\
\text { (l.) }\end{array}$ & $\begin{array}{c}\text { R.V. } \\
\text { (i.) }\end{array}$ & $\begin{array}{c}\mathrm{SGaw} \\
\left(\mathrm{cm} . \mathrm{H}_{2} \mathrm{O}^{-1}\right. \\
\left.\mathrm{sec}^{-1}\right)\end{array}$ & $\begin{array}{c}\text { TLco } \\
\text { (ml./min./ } \\
\text { mm.Hg) }\end{array}$ & $\underset{\left(\mathrm{min}^{-1}\right)}{\mathrm{kco}}$ \\
\hline $\begin{array}{l}\text { F.I. } \\
\text { M.H. } \\
\text { R.W. } \\
\text { K.B. } \\
\text { H.T. } \\
\text { D.L. } \\
\text { E.P. } \\
\text { D.H. } \\
\text { B.Mc. } \\
\text { E.C. }\end{array}$ & $\begin{array}{l}1 \cdot 30 \\
2.75 \\
2.90 \\
1.20 \\
2.55 \\
2.10 \\
2.45 \\
1.40 \\
1.65 \\
1 \cdot 75\end{array}$ & $\begin{array}{l}1.90 \\
3.40 \\
3.80 \\
2.20 \\
2.65 \\
2.60 \\
3.20 \\
1.90 \\
2.00 \\
2.20\end{array}$ & $\begin{array}{l}3 \cdot 30 \\
3 \cdot 95 \\
5 \cdot 90 \\
5 \cdot 55 \\
3 \cdot 75 \\
-\overline{4 \cdot 10} \\
2 \cdot 85 \\
3 \cdot 55 \\
4 \cdot 78\end{array}$ & $\begin{array}{l}1.40 \\
0.55 \\
2.10 \\
3.35 \\
1.10 \\
-\overline{0.90} \\
0.95 \\
1.55 \\
2.58\end{array}$ & $\begin{array}{l}0.24 \\
0.59 \\
0.24 \\
0.20 \\
0.48 \\
0.50 \\
0.69 \\
0.43 \\
0.43\end{array}$ & $\begin{array}{r}11 \cdot 5 \\
16 \cdot 6 \\
17 \cdot 0 \\
17 \cdot 2 \\
18 \cdot 3 \\
10 \cdot 8 \\
23 \cdot 1 \\
7 \cdot 4 \\
14 \cdot 5 \\
10 \cdot 2\end{array}$ & $\begin{array}{l}3 \cdot 2 \\
3 \cdot 2 \\
2 \cdot 8 \\
4 \cdot 0 \\
4 \cdot 1 \\
2 \cdot 9 \\
4 \cdot 1 \\
2 \cdot 0 \\
4 \cdot 9 \\
1 \cdot 8\end{array}$ \\
\hline
\end{tabular}

T A B L E I I I

PHYSIOLOGICAL DATA ON PATIENTS WITH ABNORMAL RESPONSE TO EXERCISE

\begin{tabular}{|c|c|c|c|c|}
\hline & D.H. & E.C. & B.Mc. & E.P. \\
\hline 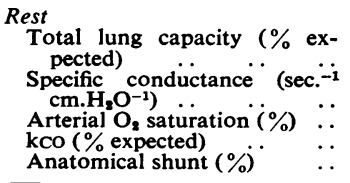 & $\begin{array}{l}74 \\
0 \cdot 68 \\
95 \\
60 \\
5\end{array}$ & $\begin{array}{l}74 \\
0 \cdot 49 \\
96 \\
50 \\
5\end{array}$ & $\begin{array}{c}79 \\
0 \cdot 43 \\
(94) \\
120 \\
-\end{array}$ & $\begin{array}{l}108 \\
0 \cdot 50 \\
96 \\
120 \\
4\end{array}$ \\
\hline 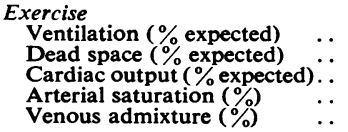 & $\begin{array}{r}144 \\
207 \\
67 \\
86 \\
19\end{array}$ & $\begin{array}{r}121 \\
185 \\
115 \\
86 \\
33\end{array}$ & $\begin{array}{r}175 \\
(174) \\
(77) \\
(88) \\
(18)\end{array}$ & $\begin{array}{r}140 \\
226 \\
94 \\
96 \\
4\end{array}$ \\
\hline
\end{tabular}

Values in parentheses were calculated indirectly (see text).

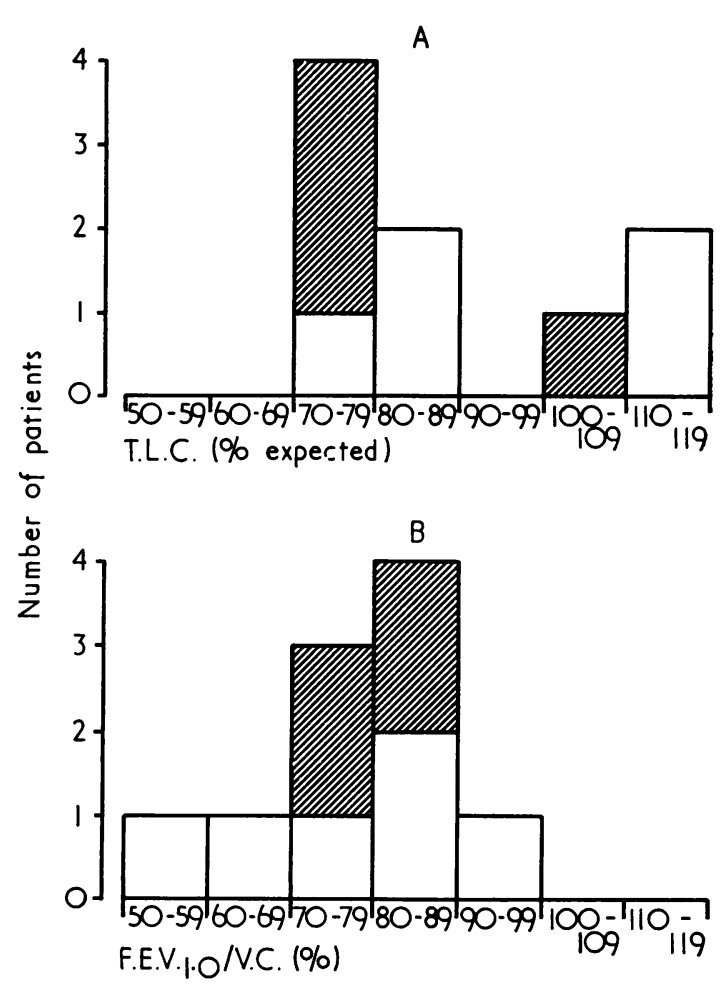

FIG. 1. Distribution of total lung capacity (T.L.C.) and spirometry. The shaded columns in this and the next figure represent four patients with a markedly abnormal response to exercise.

II. The T.L.C. varied from 74 to $119 \%$ of the expected value for the subject (Fig. 1A). The patients represented by shaded columns or crosses in the figures presented a fairly uniform picture in terms of their response to exercise and also tended to have the worst conventional lung function of the group (Table III): they are discussed fully later. The results for residual volume (R.V.) were similar and have not been shown in the Figure. The ratio R.V./T.L.C. was within normal limits for the patients' age with the exception of one (K. B.) in which it was $60 \%$. The V.C. varied from 63 to $115 \%$ of the predicted and the ratio of the F.E.V. ${ }_{1}$ to the V.C. expressed as a percentage was normal (above $70 \%$ ) in all but two patients (Fig. 1B). The absence of airways obstruction was confirmed in all nine patients in which it was measured by the finding of SGaw greater than $0.19 \mathrm{~cm} \cdot \mathrm{H}_{2} \mathrm{O}^{-1} . \mathrm{sec}^{-1}$

The TLco was reduced in all patients except one (Fig. 2A). It fell to its lowest value in two patients, later shown to have gross ventilation/perfusion imbalance. When the results were expressed as the 
kco the differences were interesting (Fig. 2B). It has been shown that the kco expresses the ability of the lungs to transfer $\mathrm{CO}$ in terms which are virtually independent of the alveolar volume (McGrath and Thomson, 1959), and the normal value can be predicted from the subject's age. Five patients had normal kco values and five patients had low values of kco. The lowest value $(50 \%)$ was obtained for E.C., who had the most severe desaturation and ventilation/perfusion imbalance on exercise. These results suggest that the ability to transfer $\mathrm{CO}$ was normal in relation to lung volume in five patients despite the low values obtained for TLco.

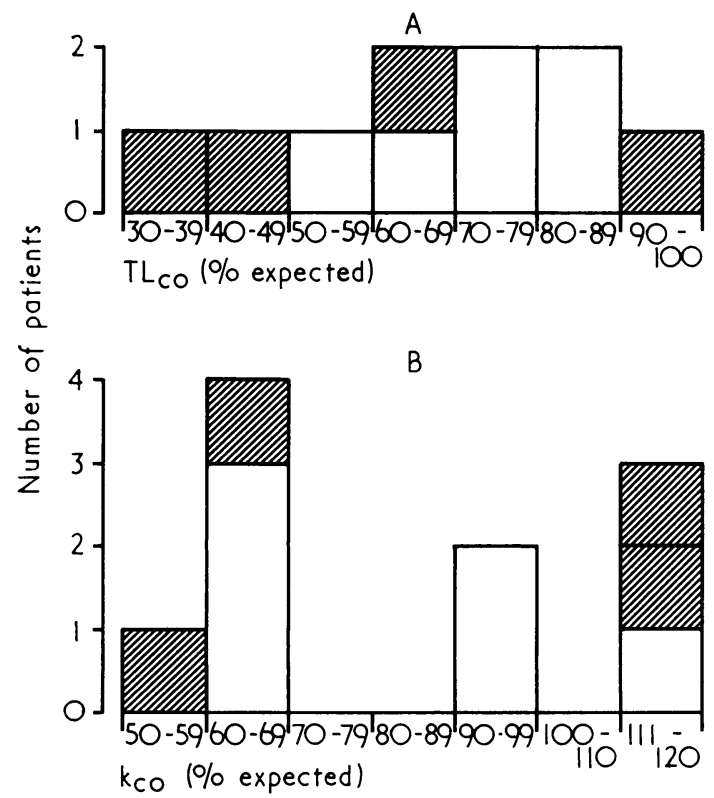

FIG. 2. Distribution of the transfer factor for $C O$ (TLco) and Krogh's constant $(k \mathrm{co})$. For code see Figure 1.

RESPONSE TO EXERCISE All the patients had a diminished performance on the cycle ergometer. Some patients were only able to perform 100 $\mathrm{kpm} . / \mathrm{min}$. (16 W) and only two were able to reach $400 \mathrm{kpm} . / \mathrm{min}$. (64 W). We should have expected the younger patients to have reached $800 \mathrm{kpm} . / \mathrm{min}$. and the older ones about 600 $\mathrm{kpm} . / \mathrm{min}$. The reasons given for stopping were usually breathlessness, fatigue, or aching legs, but there was no correlation between the subjective reasons and the physiological results. No patient suffered from angina pectoris during the test and there was no change in the waveform of the E.C.G. in any case.
At the highest work load achieved, the tota店 minute ventilation (VE) was excessive in fou? patients (Fig. 3A). Since the tidal volume (Vt) wa호․ usually normal (Fig. 3B), this increase in ventila $\frac{\bar{s}}{5}$ tion was achieved by an increased rate of breathing.
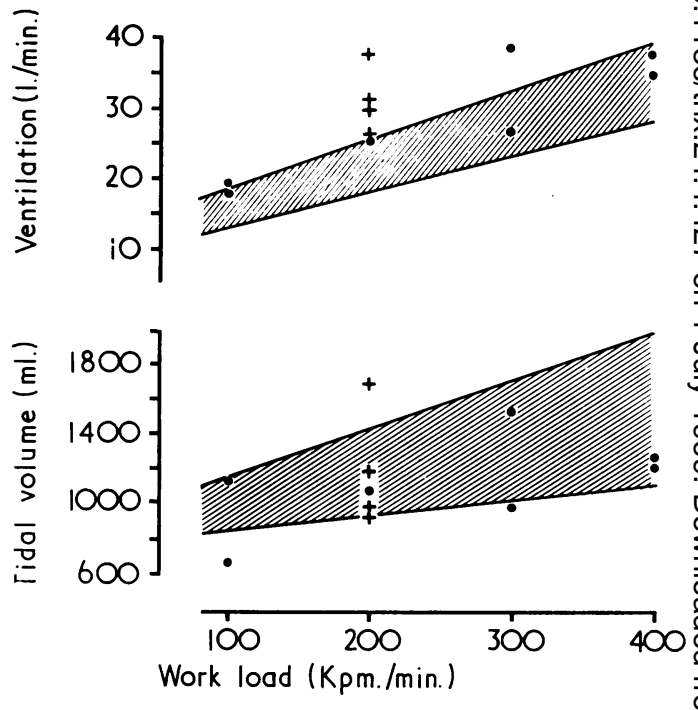

FIG. 3. Ventilation and tidal volume for each patient at the highest work load achieved. The shaded band represent the normal range ( $\pm 1 S . D$.$) ; the patient?.$ shown by + correspond to those shown as shaded block in the previous figures.

Resting values of $\mathrm{SaO}_{2}$ were within the expected normal range in all but one patient (E. C.), who had an $\mathrm{SaO}_{2} 3.5 \%$ below expected. The measure $\mathrm{SaO}_{2}$ at the highest work load achieved are shown in Fig. 4A. One patient (D. L.), who had a signio ficantly low $\mathrm{SaO}_{2}$ on exercise $(5.7 \%$ below the expected value), had suffered from pulmonary. emboli in the past. Three others showed marked desaturation on exercise, varying from 10.5 to $13.5 \%$ below expected. This represented falls in saturation of 7 to $10 \%$ compared with the expected rest and exercise values. The remainder were normal.

Oxygen consumption tended to be rather lowed than expected (Fig. 4B), but this is of doubtfut significance. The respiratory exchange ratiog $\left(\mathrm{VCO}_{2} / \mathrm{Vo}_{2}=\mathbf{R}\right)$ was high in most patients, irre spective of their other responses to exercise (Fi\& 5A). This was partly due to alveolar hyperventil tion as shown by the low $\mathrm{PaCO}_{2}$ levels (Table III and partly due to excessive anaerobic metabolis as revealed by the high levels of blood lacta? 

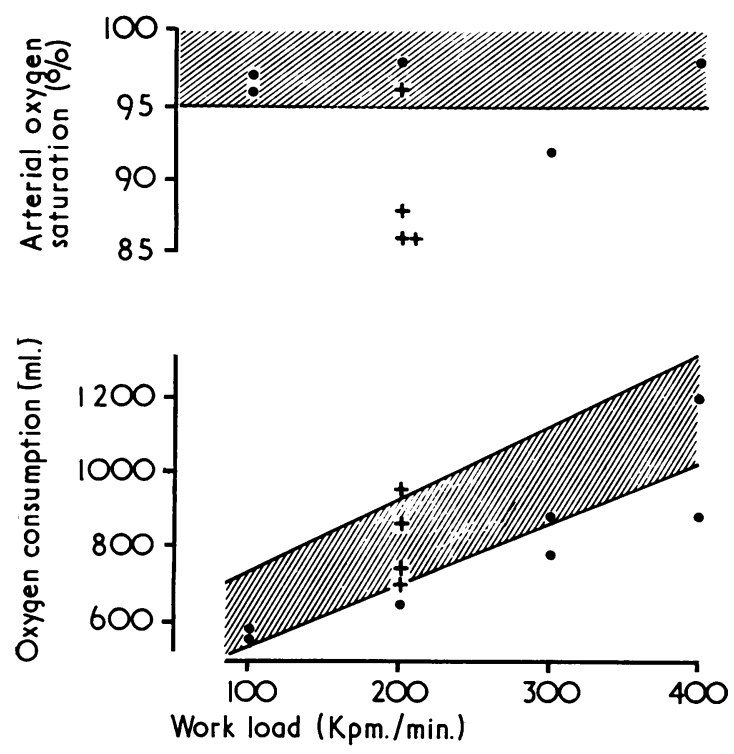

FIG. 4. Arterial saturation and oxygen consumption for each patient at the highest work load achieved. Symbols as before.
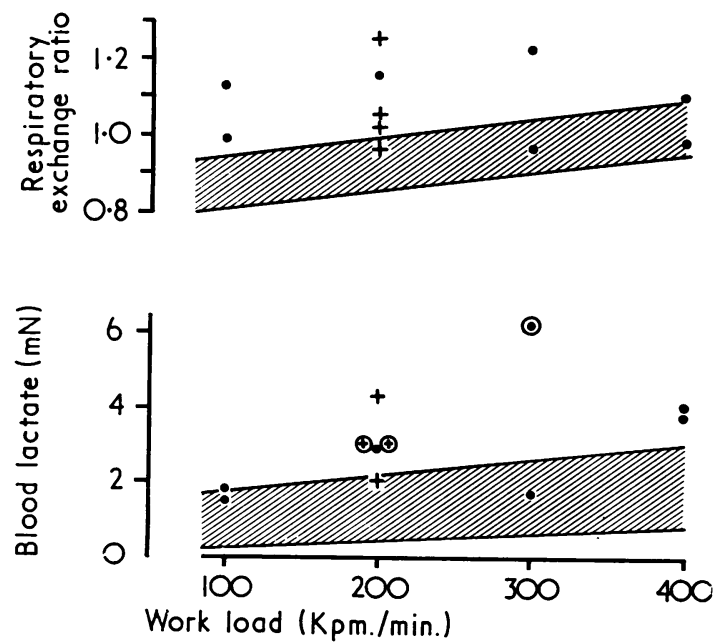

FIG. 5. Respiratory exchange ratio $\left(\dot{\mathrm{V}} \mathrm{CO}_{2} / \dot{\mathrm{VO}}_{2}\right)$ and blood lactate for each patient at the highest work load achieved. The ringed points were measured directly, and the rest calculated (see text). Symbols as before.

(Fig. 5B). The lactate values in Fig. 5 were calculated from the balance equation for $\mathrm{CO}_{2}$, and a resting lactate of $0.7 \mathrm{mN}$ was assumed. The actual blood lactate was measured in three cases (ringed points) and a comparison with the calculated value showed the latter to be up to $1.0 \mathrm{mN}$ too low. The blood lactate was particularly high in R. W., K. B., H. T., D. L., D. H., and B. M. It is noteworthy that three of them also had skeletal muscle abnormalities (Table IV).

T A B L E I V

SYSTEMS INVOLVED BY DISEASE

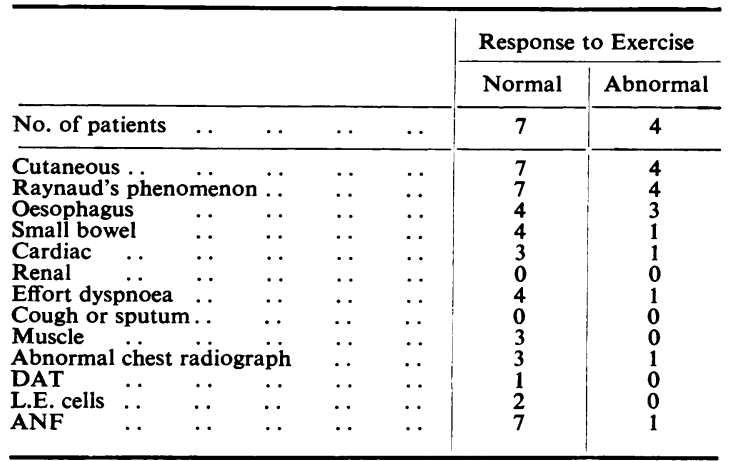

$\mathrm{DAT}=$ differential agglutination; $\mathrm{ANF}=$ antinuclear factor.

The equations described previously were solved graphically for each patient at the highest work load to give the following pairs of co-ordinates:

(a) the $\mathrm{Vd}$ for the highest likely $\mathrm{Q}$

(b) the $\mathrm{Q}$ for the lowest likely $\mathrm{Vd}$

(c) the probable values for $\mathrm{Vd}$ and $\mathrm{Q}$ based on an arterial $\mathrm{PCO}_{2}$ calculated from the end tidal $\mathrm{PCO}_{2}$.

These co-ordinates, together with the actual solution for the four blood studies, are given in Table $\mathrm{V}$. The lines joining the three points for each patient have been plotted in Fig. 6, together with single points representing the actual values for $\mathrm{Vd}$ and $Q$ for those patients from whom arterial blood was taken. The lines represent all possible solutions in the likely range of the relationship between Vd and $Q$ for each patient and the point on the line represents the probable solution based on the end tidal $\mathrm{PCO}_{2}$. It can be seen that one patient $(\triangle)$ must have been normal, because whatever values of $\mathrm{Vd}$ and $\mathrm{Q}$ represented by the line were actually correct, they would inevitably lie within the normal range. The other five patients represented by open or half open symbols were also thought to be normal even though their lines extended outside the conventional normal range. This was because the probable solution in each case indicated a normal or minimally increased Vd and a low or normal $Q$. This was quite a different picture from that of the patients represented by closed symbols, which is discussed below. One patient with relatively mild changes had a blood study and she did have a normal Vd and a definitely low $Q$, but this woman had a history of pulmonary emboli in the past and her present study showed an improvement on previous studies. 
T A B L E V

\begin{tabular}{|c|c|c|c|c|c|c|c|}
\hline Patient & $\begin{array}{c}\text { Ex- } \\
\text { pected } \\
\mathbf{Q} \\
(1 . / \mathrm{min} .)\end{array}$ & $\begin{array}{c}\text { Ex- } \\
\text { pected } \\
\text { Vd } \\
(\mathrm{ml} .)\end{array}$ & $\begin{array}{l}\text { Prob- } \\
\text { able } \\
\mathrm{PaCO}_{2} \\
(\mathrm{~mm} . \\
\mathrm{Hg})\end{array}$ & $\begin{array}{c}\text { Prob- } \\
\text { able } \\
\mathbf{Q} \\
\text { (1./min.) }\end{array}$ & $\begin{array}{c}\text { Prob- } \\
\text { able } \\
\text { Vd } \\
\text { (ml.) }\end{array}$ & $\begin{array}{l}Q \text { for } \\
\text { lowest } \\
\text { likely } \\
\text { Vd }\end{array}$ & $\begin{array}{c}\text { Vd for } \\
\text { highest } \\
\text { likely } \\
\text { Q }\end{array}$ \\
\hline $\begin{array}{l}\text { F.I. } \\
\text { M.H. } \\
\text { R.W. } \\
\text { K.B. } \\
\text { H.T. } \\
\text { S.P. } \\
\text { D.L. }{ }^{1} \\
\text { E.P. }{ }^{1} \\
\text { D.H. }{ }^{1} \\
\text { B.Mc. } \\
\text { E.C. }{ }^{1}\end{array}$ & $\begin{array}{l}10.0 \\
10.5 \\
12.0 \\
11.0 \\
13.2 \\
11.0 \\
12.7 \\
11.3 \\
11.1 \\
11.7 \\
12.2\end{array}$ & $\begin{array}{l}161 \\
186 \\
189 \\
183 \\
193 \\
178 \\
208 \\
190 \\
177 \\
178 \\
270\end{array}$ & $\begin{array}{l}36 \cdot 0 \\
40 \cdot 0 \\
31 \cdot 5 \\
33 \cdot 0 \\
35 \cdot 0 \\
32 \cdot 5 \\
30 \cdot 5 \\
40 \cdot 5 \\
39 \cdot 0 \\
33 \cdot 0 \\
47 \cdot 0\end{array}$ & $\begin{array}{r}7.5 \\
11.0 \\
11.5 \\
7 \cdot 3 \\
10.7 \\
7 \cdot 3 \\
7 \cdot 7 \\
10.6 \\
7 \cdot 4 \\
8 \cdot 5 \\
14.0\end{array}$ & $\begin{array}{l}170 \\
180 \\
215 \\
210 \\
280 \\
185 \\
245 \\
430 \\
365 \\
310 \\
500\end{array}$ & $\begin{array}{r}5 \cdot 5 \\
9 \cdot 0 \\
10 \cdot 0 \\
6 \cdot 0 \\
9 \cdot 0 \\
6 \cdot 3 \\
- \\
- \\
7.8 \\
\end{array}$ & $\begin{array}{l}230 \\
190 \\
300 \\
380 \\
380 \\
360 \\
- \\
- \\
\overline{4} \\
-\end{array}$ \\
\hline
\end{tabular}

${ }^{1}$ Blood study giving actual $\mathrm{Q}$ and $\mathrm{Vd}$.

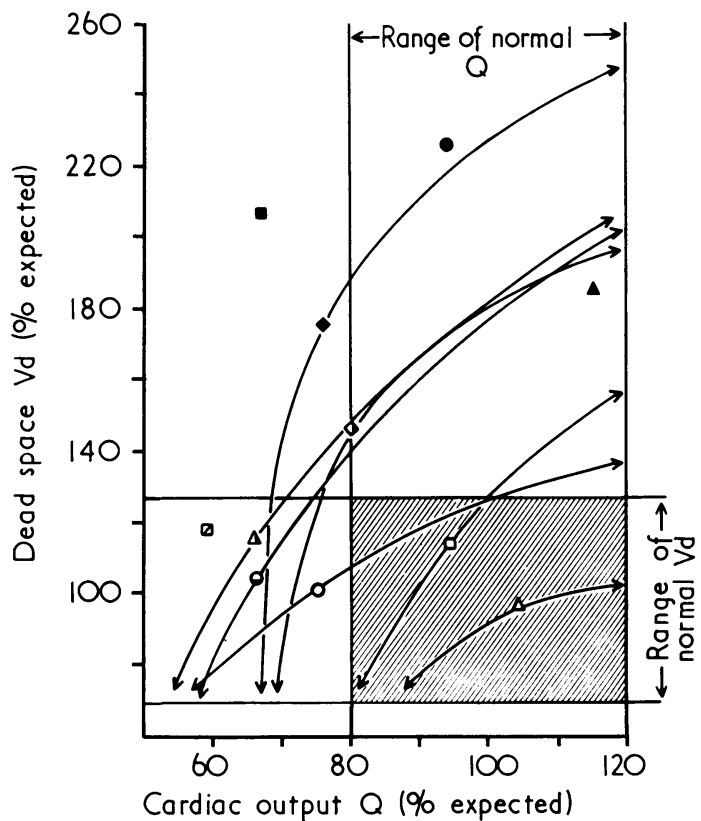

FIG. 6. The possible limits of dead space and cardiac output for each patient at the highest work load achieved. The normal range for each parameter is given and the shaded area represents both a normal dead space and a normal cardiac output. The lines plot the possible solutions for each patient and the central point on the line indicates the probable solution. The 4 lone points represent the studies in which analysis of arterial blood provided $a$ definite solution. The closed symbols refer to the 4 patients shown by shaded blocks or crosses in previous figures. A full explanation is given in the text.

Four patients were thought to show marked change on initial exercise testing and blood studies in three of them gave a picture of relatively normal $Q$ but a definitely increased Vd. One of these patients (B. Mc.) is represented by a line because we could not repeat the study with arterial sampling owing to the severity of her Raynaud's $\overrightarrow{\bar{B}}$ phenomena. This line illustrates the gross devia- $\overline{0}$ tion from the normal range which was found in 음 this group, and it contrasts with the lines for the $\frac{\bar{\sigma}}{\sigma}$ relatively normal patients. It is less certain where $\mathbb{\otimes}$ the correct solution lies with such an abnormal line as this, but end tidal $\mathrm{PCO}_{2}$ indicated a low ${ }^{\infty}$ normal $Q$ and a high Vd. This woman showed $\vec{O}$ considerable arterial desaturation on exercise $\overrightarrow{\vec{\omega}}$ (determined by ear oximetry).

The venous admixture ratio was calculated for $\overrightarrow{\vec{x}}$ all patients in whom arterial saturation was i measured directly or from ear oximetry. This ratio was considerably increased in the three patients who desaturated most on exercise. All patients who had blood studies were given $100 \%$ oxygen 을 to breathe until all the $\mathbf{N}$, was flushed out of their lungs (determined from the expired gas analysis). The arterial saturation in these circumstances was used to calculate the 'anatomical' component of $\vec{\theta}$ the venous admixture, which was found to be less than $5 \%$ in every case.

\section{DISCUSSION}

The changes we have found in the conventional $\frac{2}{\mathbb{Q}}$ tests of lung function are similar to those described $\overrightarrow{\vec{A}}$ by previous investigators. It is generally agreed을 that the lungs are smaller than normal in systemic sclerosis, the vital capacity is reduced and theo F.E.V..$_{1}$, though reduced, occupies a normal percentage of the V.C. (Miller, Fowler, and Helm-o holz, 1959 ; Conner and Bashour, 1961 ; Adhikari,叉ָ Bianchi, Boushy, Sakamoto, and Lewis, $1962 ; 0$ Hughes and Lee, 1963; Ritchie, 1964). These changes are typical of the small lungs found in pulmonary fibrosis from any cause. Some observers have found an obstructive picture in ao small number of their patients (Pariente, Khoury Roger, and Brouet, 1967) and two of our subjectso had an F.E.V., below 70\%. However, a direct measurement of specific airways conductance showed a normal airways resistance in our patients, so that their defect was purely restrictive

In general terms we have confirmed the previous finding that the transfer factor for $\mathrm{CO}$ (TLco) i\$ reduced in systemic sclerosis (Adhikari et al. 1962; Hughes and Lee, 1963; Catterall and? Rowell, 1963 ; Ritchie, 1964). This has often beeno interpreted as indicating an 'alveolar-capillar ${ }_{0}$ block', but a reduction in transfer of $\mathrm{CO}$ can b due to several factors, including a reduction irip the surface area available for diffusion and ventio lation/perfusion disturbances. In our patients we have shown that the transfer of $\mathrm{CO}$ was actuall 
appropriate to the lung volume in five cases and low in five. This suggests that the low Tuco found in previous studies may really be a reflection of the small size of the lungs in many patients with systemic sclerosis.

The bloodless approach to the study of exercise in the present paper has been fully discussed elsewhere (Higgs et al., 1967; McHardy et al., 1967). We used this method as a screening test for all our patients because a normal response during a bloodless test would avoid the need for arterial puncture in patients with a tendency to vascular disease. In those patients in whom the bloodless test was abnormal, we attempted to repeat the study in order to obtain the true results by taking arterial blood, but failed to catheterize the artery of one of them (B. Mc.).

All our patients were severely limited in their effort tolerance. Other studies involving exercise have also reported results at only relatively low levels of work (Aquilani, Castagnoli, Crispo, and Zorin, 1967 ; Ashba and Ghanem, 1965). In some of our patients we are able to suggest possible causes for this inability to exercise.

Thus the four most severely affected patients all showed a similar response to exercise with a large dead space and relatively normal cardiac output. In addition, three of them also had a considerable venous admixture effect which became normal when breathing $100 \% \mathrm{O}_{2}$. These changes indicate gross ventilation/perfusion imbalance. In the patient who did not desaturate, the changes could also be explained on the basis of pulmonary vascular disease, and it is interesting that this has been described in systemic sclerosis (Naeye, 1963). All of these patients had a high ventilation on exercise and they tended to have the smallest lungs and least ability to transfer $\mathrm{CO}$ (Table III). Previous workers have noted hyperventilation on exercise (Ritchie, 1964 ; Fuleihan, Kurban, Abboud, Beidas-Jubran, and Farah, 1968), desaturation on exercise (Ashba and Ghanem, 1965 ; Aquilani et al., 1967), and an increased venous admixture at rest (Fuleihan et al., 1968). In the remaining seven patients we have not been able to explain their effort intolerance. In general the cardio-respiratory responses were within acceptable limits. It seems likely that prolonged immobility due to joint fixation adversely affected their ability to stress themselves. The elevation of blood lactate in many of these patients was generally similar to that seen in unfit normal subjects of the same age, but the high levels found in some of our patients might point to muscle involvement which has recently been noted in this condition (Thompson, Bluestone, Bywaters, Dorning, and Johnson, 1969).

Previous observers have found little correlation between the clinical condition and the results of conventional lung function tests (Weaver et al., 1967 ; Ashba and Ghanem, 1965). Although we have shown that the patients with the most abnormal response to exercise tended to have the most abnormal lung volumes, spirometry, and transfer ability for $\mathrm{CO}$, we have been unable to correlate the clinical state with our physiological data (Table IV). This may be due to the smallness of our series, or more likely it may result from the patients' general lack of mobility.

It is important to detect pulmonary involvement so that the patient may be guarded from the added dangers of bronchial infection. The simple screening tests of spirometry, TLco and kco should best be supplemented by a bloodless exercise test to provide a realistic profile.

We wish to thank Professor E. G. L. Bywaters and Dr. P. J. L. Holt for permission to study their patients, and Dr. E. J. M. Campbell and Dr. N. L. Jones for advice on the preparation of the manuscript.

\section{REFERENCES}

Adhikari, P. K., Bianchi, F. A., Boushy, S. F., Sakamoto, A., and Lewis, B. M. (1962). Pulmonary function in scleroderma. Amer. Rev. resp. Dis., 86, 823.

Aquilani, M., Castagnoli, M., Crispo, M., and Zorzin, L. (1967). Contributo casistico allo studio del polmone sclerodermico. Rif. med., 15, 398.

Ashba, J. K., and Ghanem, M. H. (1965). The lungs in systemic sclerosis. Dis. Chest, 47, 52.

Catterall, M., and Rowell, N. R. (1963). Respiratory function in progressive systemic sclerosis. Thorax, 18, 10.

Clode, M. (1966). $\mathrm{CO}_{2}$ balance during exercise. J. Physiol. (Lond.), $184,49 P$.

Collins, M. M., McDermott, M., and McDermott, T. J. (1964). Bellows spirometer and transistor timer for the measurement of forced expiratory volume and vital capacity. Ibid., 172, 39P.

Conner, P. K., and Bashour, F. A. (1961). Cardiopulmonary changes in scleroderma. A physiologic study. Amer. Heart J., 61, 494.

Cotes, J. E. (1965). Normal values for TLco. Lung Function. Blackwell Scientific Publishers, Oxford.

Freedman, S., and Prowse, K. (1966). How many blows make an F.E.V.1.0? Lancet, $2,618$.

Fuleihan, F. J. D., Kurban, A. K., Abboud, R. T., Beidas-Jubran, N., and Farah, F. S. (1968). An objective evaluation of the treatment of systemic scleroderma with disodium EDTA, pyridoxine and reserpine. Brit. J. Derm., 80, 184.

Guyatt, A. R., Alpers, J. H., Hill, I. D., and Bramley, A. C. (1967). Variability of plethysmographic measurements of airways resistance in man. J. appl. Physiol., 22, 383.

Higgs, B. E., Clode, M., McHardy, G. J. R., Jones, N. L., and Campbell, E. J. M. (1967). Changes in ventilation, gas exchange and circulation during exercise in normal subjects. Clin. Sci., 32, 329.

Hohorst, H. J. (1957). Enzymatische Bestimmung von L (+)-Milchsaüre. Biochem. Z., 328, 509.

Hughes, D. T. D., and Lee, F. I. (1963). Lung function in patients with systemic sclerosis. Thorax, 18, 16.

Jones, N. L. (1967). Exercise testing. Brit. J. Dis. Chest, 61, 169.

Campbell, E. J. M., McHardy, G. J. R., Higgs, B. E., and Clode, M. (1967). The estimation of carbon dioxide pressure of mixed venous blood during exercise. Clin. Sci., 32, 311 . 
- McHardy, G. J. R., Naimark, A., and Campbell, E. J. M. (1966). Physiological dead space and alveolar-arterial gas pressure differences during exercise. Ibid., 31, 19.

Lal, S., Gebbie, T., and Campbell, E. J. M. (1966). Simple methods for improving the value of oximetry in the study of pulmonary oxygen uptake. Thorax, 21, 50.

McGrath, M. W., and Thomson, M. L. (1959). The effect of body size and lung volume change on alveolar-capillary permeability and diffusing capacity in man. $J$. Physiol. (Lond.), 146, 572.

McHardy, G. J. R., Jones, N. L., and Campbell, E. J. M. (1967) Graphical analysis of carbon dioxide transport during exercise. Clin. Sci., 32, 289.

Miller, R. D., Fowler, W. S., and Helmholz, F. H. (1959). Scleroderma of the lungs. Proc. Mayo Clin., 34, 66.
Naeye, R. L. (1963). Pulmonary vascular lesions in systemic sclero๒ derma. Dis. Chest, 44, 374.

Needham, C. D., Rogan, M. C., and McDonald, I. (1954). Norma standards for lung volumes intrapulmonary gas-mixing and maximum breathing capacity. Thorax, 9, 313.

Pariente, R., Khoury, F., Roger, N., and Brouet, G. (1967). Les localisations pulmonaires des sclérodermies. Sem. Hôp. Paris』 43, 1309.

Ritchie, B. (1964). Pulmonary function in scleroderma. Thorax, 19, $28 \mathrm{c}$

Thompson, J., Bluestone, R., Bywaters, E. G. L., Dorning, J., and Johnson, M. (1969). Muscle involvement in systemic sclerosis In preparation.

Weaver, A. L., Divertie, M. B., and Titus, J. L. (1967). The lung in scleroderma. Mayo Clin. Proc., 42, 754. 